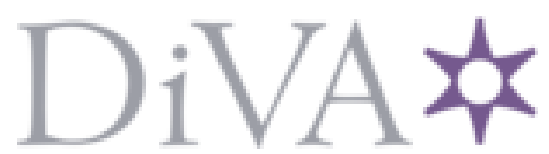

http://www.diva-portal.org

\title{
Postprint
}

This is the accepted version of a paper published in Pediatrics. This paper has been peer-reviewed but does not include the final publisher proof-corrections or journal pagination.

Citation for the original published paper (version of record):

Hailer, Y., Montgomery, S., Ekbom, A., Nilsson, O., Bahmanyar, S. (2010)

Legg-Calve-Perthes Disease and Risks for Cardiovascular Diseases and Blood Diseases.

Pediatrics, 125(6): E1308-E1315

http://dx.doi.org/10.1542/peds.2009-2935

Access to the published version may require subscription.

N.B. When citing this work, cite the original published paper.

Rewritten version of DOI: 10.1542/peds.2013-0972 (errata) and DOI: 10.1542/peds.2009-2935

Permanent link to this version:

http://urn.kb.se/resolve?urn=urn:nbn:se:uu:diva- 136077 


\title{
ERRATUM
}

(Original publication in Pediatrics 2010;125;e1308-e1315; online May 3, 2010; DOI:

10.1542/peds.2009-2935, ERRATUM published in Pediatrics 2013;132;186; DOI: 10.1542/peds.2013-

0972)

\section{Legg-Calvé-Perthes Disease and Risks for Cardiovascular Diseases and Blood Diseases}

Short title: Perthes disease and risk of cardiovascular and blood diseases

Yasmin D. Hailer ${ }^{1}$ (M.D.), Scott M Montgomery ${ }^{2,3}$ (BSc., PhD, professor), Anders Ekbom² M.D., PhD, professor), Olof S. Nilsson ${ }^{1}$ (M.D., PhD, professor), Shahram Bahmanyar2, 4 (M.D., PhD)

${ }^{1}$ Department of Orthopaedics, Uppsala University Hospital, Sweden

2 Clinical Epidemiology Unit, Department of Medicine, Karolinska University Hospital, Karolinska Institutet, Stockholm, Sweden

${ }^{3}$ Clinical Epidemiology and Biostatistics, Örebro University Hospital and Örebro University, Örebro, Sweden

4 Faculty of Medicine, Golestan University of Medical Sciences, Gorgan, Iran

\begin{abstract}
OBJECTIVE: We hypothesized that patients with Legg-Calvé-Perthes disease (LCPD) might have higher risks of cardiovascular and blood diseases.

METHODS: A total of 2579 patients with LCPD diagnosed between 1965 and 2005 were identified with the Swedish Inpatient Register. A total of 13748 individuals without LCPD were selected randomly from among the Swedish general population, with matching according to year of birth, age, gender, and region of residence. Cox proportional-hazard regression analyses, with adjustment for socioeconomic index, were used to estimate relative risks. The patients also were compared with their same-gender siblings.

RESULTS: Patients with LCPD had a hazard ratio (HR) of 1.70 (95\% confidence interval [CI]: 1.48 1.95) for cardiovascular diseases, compared with individuals without LCPD. There were statistically significantly higher risks for hypertensive disease, ischemic heart diseases, cerebrovascular diseases, diseases of arteries, veins, and lymphatic vessels. There were statistically significantly higher risks for blood diseases, including anemias and coagulation defects (HR: 1.94 [95\% CI: 1.512.49]), which were more pronounced among subjects $>30$ years of age at the follow-up (HR: 2.45 [95\% CI: 1.77-3.41]). Patients also had statistically significantly higher risks of nutritional anemia (HR: 2.32 [95\% CI: 1.41 -3.81]) and hemolytic anemia (HR: 2.59 [95\% CI: (1.72-3.92]). Analyses using siblings as the comparison group showed consistent results for cardiovascular diseases. CONCLUSION: The results are consistent with the hypothesis that an insufficient blood supply to the femoral head, attributable to vascular pathologic conditions, is involved in the pathogenesis of LCPD.
\end{abstract}

\section{KEY WORDS}

Legg-Calvé -Perthes disease, hypertension, ischemic heart disease, coagulation, risk factors 


\section{WHAT'S KNOWN ON THIS SUBJECT:}

The pathogenesis of LCPD is not completely understood, but there are indications of pathologic changes in vascular development or function. It has been hypothesized that a problem in the circulation in the femoral head is involved.

\section{WHAT THIS STUDY ADDS:}

The study shows that patients with LCPD had higher risks of cardiovascular diseases and some diseases of the blood. These associations are consistent with vascular pathologic conditions and other sources of insufficient blood supply to the femoral head.

\section{BACKGROUND}

Legg-Calvé -Perthes disease (LCPD) is an osteonecrosis of the femoral head epiphysis and is usually diagnosed among children $<15$ years of age, with a peak for onset between 5 and 8 years of age. The disease is 4 times more common among boys, and there is bilateral involvement in $8 \%$ to $24 \%$ of cases ${ }^{1}$. 3 . The reported annual incidence varies between 0.45 cases per 100000 among black children in South Africa ${ }^{4}, 0.9$ cases per 100 000 among children in Japan ${ }^{5}$, and 21 cases per 100000 among children in Liverpool, England 6. In Uppsala, Sweden, the annual incidence was identified as 8.5 cases per 100 000 among children 0 to 14 years of age in 1978 - 19897.

The cause and underlying pathophysiologic features of LCPD are not completely understood, but indications of an underlying mechanism are provided by associations with passive smoking, small stature, skeletal retardation, and low birth weight $8-13$. These observations are consistent with influences on early growth that may be relevant to vascular development or function. It has been hypothesized that a circulation problem in the femoral head, such as venous stasis attributable to increased intraarticular and intraosseous pressure 14,15 , may be etiologically relevant. It has been suggested that anatomic abnormalities resulting in decreased numbers or capacity of blood vessels may increase LCPD risk ${ }^{16-19}$. Disorders of the blood and blood-forming organs also might play a part, such as thromboembolic events resulting from changes in the coagulation system. Factor $\mathrm{V}$ Leiden mutations ${ }^{20}$, high levels of anticardiolipin antibodies ${ }^{21}$, and decreased levels of $\mathrm{C}$ and $\mathrm{S}$ proteins ${ }^{22,23}$ have been reported for patients with LCPD, but the findings are inconsistent 24 . Therefore, it is possible that there are shared risks for LCPD and some cardiovascular diseases and diseases of the blood and bloodforming organs. These shared risks might operate through inheritance or exposure to some environmental factors in early life.

In this general population-based study, we used Swedish registry data to examine the hypothesis that patients with LCPD would have a higher risk of cardiovascular diseases, consistent with the hypothesis that various abnormalities of the circulation may contribute to the pathogenesis of LCPD by interfering with the blood supply to the femoral head. Associations with diseases of the blood and blood- forming organs also were examined, because these might be relevant through mechanisms such as abnormalities of coagulation predisposing patients to thrombophilia and hemorrhage.

\section{METHODS}

Swedish registry data were used to identify a cohort of patients with a diagnosis of LCPD. This cohort was compared with a general population- based cohort without LCPD to assess the risk of cardiovascular diseases (including hypertensive diseases, ischemic heart diseases, pulmonary heart diseases and diseases of the pulmonary circulation, cerebrovascular diseases, diseases of arteries, arterioles, and capillaries, and diseases of veins, lymphatic vessels, and lymph nodes, equivalent to International Classification of Diseases, 10th Revision, codes I00-I99), as 
well as diseases of the blood and bloodforming organs (including nutritional, hemolytic, and aplastic anemias, coagulation defects, purpura, and other hemorrhagic conditions, equivalent to International Classification of Diseases, 10th Revision, codes D50 -D89). A comparison cohort of siblings of patients with LCPD also was used. Registry data linkage was possible through the use of the unique personal registration numbers issued to all Swedish residents.

The Swedish Inpatient Register includes data on individual hospital admissions and was used to identify 2579 patients with International Classification of Diseases codes for LCPD (Inter- national Classification of Diseases, Seventh Revision, code 732.04; International Classification of Diseases, Eighth Revision, code 722.11; International Classification of Diseases, Ninth Revision, code 732B; and International Classification of Diseases, 10th Revision, codes M91.1 and M91.2) 25, 26, diagnosed between 1965 and 2005.

Subjects with LCPD were matched individually with up to 5 members of the Swedish general population who did not have the disease. The matching criteria were date of birth, region of residence (county), and gender. The matched individuals had to be alive at the time the patient received the diagnosis of LCPD. We were not able to find matching individuals for 3 patients, and they were excluded. In total, we included 2579 patients with LCPD and 13748 individuals without the disease in the study.

Administrative registries were used to identify information on dates of birth, death, immigration, and emigration, to calculate the follow-up period available for each individual. Census data were used to create a 6-category socioeconomic index on the basis of parents' occupations (manual workers, non-manual workers, professionals, self-employed workers, farmers, and others). The characteristics of the study group are shown in table 1.

The Swedish Multi-Generation Register identifies first-degree relatives ${ }^{27}$ and was used to identify siblings of the study subjects.
We used only same-gender siblings of the patients with LCPD; when there were $>2$ siblings, we used the sibling with the smallest age difference. This yielded data on 1552 same-gender siblings. There were 721 samegender younger siblings, 831 same-gender older siblings. The study was approved by the research ethics committee of the Karolinska Institute (Stockholm, Sweden) and complied with the Declaration of Helsinki.

Cox proportional-hazard regression analysis was used to estimate the risk of cardiovascular diseases; the cohort of patients with LCPD was compared with the cohort without LCPD. Separate models examined diseases of the blood and blood-forming organs. Follow-up monitoring was from 1965, when the Inpatient Register was established, or from birth or immigration if this occurred subsequently. Follow-up monitoring continued until diagnosis of cardiovascular diseases or diseases of the blood and bloodforming organs, death, emigration, or December 31, 2005.

Each person could have more than 1 study end point (different disease outcomes). The underlying time scale for all models was attained age. The analyses were both unadjusted and adjusted for socioeconomic index. All models were internally stratified according to risk set. Events that occurred within 5 years after LCPD diagnosis were excluded for assessment of potential surveillance bias. Analyses also were stratified according to gender, age at final follow-up point ( $\leq 30$ years or $>30$ years), and temporal sequence of LCPD and cardiovascular disease (which disease occurred first).

In supplemental analyses, we examined the following specific diseases by using Cox regression analyses: hypertension, ischemic heart diseases, pulmonary heart diseases and diseases of the pulmonary circulation, cerebrovascular diseases, diseases of the veins, lymphatic vessels and lymph nodes, coagulation defects and nutritional and hemolytic anemia. As an additional comparison group, we used same-gender siblings of the patients with LCPD with the 
smallest age difference. The siblings without a diagnosis of LCPD who were closest in age to the index subjects were selected. The risk of cardiovascular diseases and diseases of the blood and blood-forming organs was assessed when patients with LCPD were compared with their siblings. We also performed analyses with data restricted to younger or older siblings. All statistical analyses were performed by using SAS 9.1 (SAS Institute, Cary, NC).

\section{RESULTS}

\section{Cardiovascular Disease}

Patients with LCPD had a 70\% higher risk of cardiovascular diseases, compared with gender- and age-matched individuals without LCPD (Table 2), which yielded a statistically significant hazard ratio (HR) of 1.70 (95\% confidence interval [CI] 1.48 -1.95). Adjustment for socioeconomic index did not change the results notably. Of all cardiovascular diseases, the risks of hypertensive diseases (HR: 2.19 [95\% CI: 1.70- 2.81]), ischemic heart diseases (HR: 1.59 [95\% CI: $1.24-2.05]$ ), cerebrovascular diseases (HR: 1.79 [95\% CI: 1.36-2.36]), diseases of arteries, arterioles and capillaries (HR: 1.91 [95\% CI: 1.29-2.82]), diseases of veins, lymphatic vessels, and lymph nodes (HR: 1.73 [95\% CI: 1.31- 2.28]) among patients with LCPD were higher and statistically significant. Exclusion of events that occurred in the 5 years after LCPD diagnosis did not change the estimate notably (HR: 1.59 [95\% CI: 1.35-1.87]). Analyses stratified according to the temporal sequence of LCPD and cardiovascular diseases revealed a HR of 1.28 (95\% CI: 1.00 - 1.63) for cardiovascular diseases diagnosed before LCPD and a HR of 1.94 (95\% CI: 1.64-2.29) for cardio- vascular diseases diagnosed after LCPD. Analyses stratified according to age at the end of the follow-up period showed that the HRs for subjects $\leq 30$ were 1.74 (95\% CI: $1.12-2.70$ ) and for subjects $>30$ years of age 1.66 (95\% CI: 1.43- 1.94). Stratification according to gender and age at the end of the follow-up period $(\leq 30$ or $>30$ years of age) did not change the point estimates notably (data not shown).

\section{Diseases of Blood and Blood- Forming Organs}

Patients with LCPD had an almost 2-fold higher risk of diseases of the blood and bloodforming organs, including nutritional, hemolytic, and aplastic anemias, coagulation defects, purpura, and other hemorrhagic conditions (Table 2), compared with individuals without LCPD (HR: 1.94 [95\% CI: 1.51-2.49]). Adjustment for socioeconomic index did not change the results notably, and neither did exclusion of events 5 years after LCPD diagnosis (HR: 1.92 [95\% CI: 1.48 2.50]). Analyses stratified according to the temporal sequence of LCPD and diseases of the blood and blood-forming organs yielded a HR of 1.20 (95\% CI: 070-2.06) for diseases of the blood and blood-forming organs diagnosed before LCPD and a HR of 2.30 (95\% CI: 1.73-3.06) for diseases of the blood and blood-forming organs diagnosed after LCPD. Analyses stratified according to gender did not change the point estimates substantially (data not shown). Analysis stratified according to age at the final follow-up visit ( $\leq 30$ or $>30$ years of age) revealed that, whereas risk was increased among patients $>30$ years of age at the follow-up visit (HR: 2.45 [95\% CI: 1.77-3.41]), patients with LCPD who were $\leq 30$ years of age at the follow-up visit did not have any significant risk (HR: 0.97 [95\% CI: $0.54-1.75]$ ).

The analyses for more-specific outcomes revealed statistically significantly increased risk of nutritional anemia among patients with LCPD (HR: 2.32 [95\% CI: 1.41-3.81]) and hemolytic anemia (HR: 2.59 [95\% CI: (1.723.92]). The increased risk for coagulation defects was not statistically significant. When we estimated the risks of coagulation defects with disposition to thrombosis (i.e., protein $\mathrm{C}$ deficiency) ${ }^{28}$, we observed a HR of 2.93, although with a wide CI (95\% CI: 0.65-13.32) because of sparse data. The risk estimate for a coagulation defect with disposition to 
hemorrhage (i.e., decreased von Willebrand factor levels) was 1.05 (95\% CI: $0.54-2.04)$.

\section{Siblings as Comparison Cohort}

Patients with LCPD had more than two-fold risk of cardiovascular diseases, compared with their same-gender siblings (HR: 2.28 [95\% CI: 1.49-3.21] Table 3). When the patients were compared with their younger siblings and older siblings, separately, the same patterns of increased risk for cardiovascular diseases were observed in both analyses. There was a non-significant $60 \%$ increased risk for diseases of the blood and blood-forming organs of the patients, compared with their siblings and stratification for younger and older siblings result in a borderline significant increased risk for the latter analysis (HR: 2.00 [95\% CI 1.00-4.00]).

\section{DISCUSSION}

This general population- based study found that LCPD was associated with greater risk of cardiovascular diseases and diseases of the blood and blood-forming organs. Specific risks were for hypertensive diseases, ischemic heart diseases, cerebrovascular diseases, diseases of arteries, arterioles and capillaries and diseases of the veins, lymphatic vessels, and lymph nodes. These findings provide more evidence of cardiovascular involvement in the pathogenesis of LCPD. This supports our hypothesis that cardiovascular diseases would be observed more frequently among patients with LCPD, because these diseases share some common risks through inheritance or exposure.

The increase in cardiovascular disease risk among patients with LCPD is consistent with previous laboratory and experimental findings. Hresko et $\mathrm{al}^{29}$ found higher levels of lipoprotein(a), which is well-established risk factor for cardiovascular diseases ${ }^{30}$, 31, in children with LCPD. In an experimental study, Hirano et $\mathrm{al}^{32}$ induced LCPD in spontaneously hypertensive rats. This indicates that an ischemic vascular insult can lead to typical osteonecrosis of the growing femoral head in rats, resembling LCPD in children.

More evidence for the possible role of vascular abnormalities in the pathogenesis of LCPD comes from identification of common risks for LCPD and cardiovascular diseases, including low birth weight 12, 33, 34. Maternal and passive smoking during pregnancy has been implicated in the pathogenesis of atherosclerosis 35 , 36, hypertension among children ${ }^{37}$ and LCPD ${ }^{8}$. However, angiographic and venographic studies did not find any radiologically visible pathologic features in the femoral head vessels of patients with LCPD $16,38,39$. We did not identify any published histologic studies of vascular pathologic conditions associated with LCPD. The 2-fold higher risk for nutritional anemia in patients with LCPD is consistent with the results of an experimental study in which changes in femoral head growth in experimentally induced chronic anemia in rabbits were observed ${ }^{40}$. Higher risk for LCPD in patients with sickle cell anemia or thalassemia also was reported 23 , 41-44. Our finding of a 2.5-fold increased risk for hemolytic anemia provides additional evidence of a role for anemia.

We observed an elevated risk of coagulation defects, especially coagulation disorders with disposition to thrombosis, such as thrombophilia, activated protein $C$ resistance, and antiphospholipid antibody syndrome, although findings were based on few cases and were not statistically significant; however, the findings are consistent with our hypothesis. Patients with LCPD have lower protein $C$ levels, resistance to protein $C$, or protein $S$ deficiency ${ }^{22}, 45,46$. It also has been reported that these patients might have coagulation abnormalities such as mutations in the factor $\mathrm{V}$ gene (Leiden), higher levels of anticardiolipin antibodies, or hereditary thrombophilia 21, 22, 46-48, although results are inconsistent 24, 29, 49-51.Overall, the previous findings and our results are consistent with the hypothesis that various abnormalities of the circulation may contribute to the pathogenesis of LCPD by interfering with the blood supply to the femoral head.

We used same-gender siblings of patients 
with LCPD with the smallest age difference as an additional comparison group. The potential advantage of using this comparison group is that the close matching for some familial characteristics further reduces the risk of confounding. We observed similar risk patterns of higher cardiovascular disease risk among patients with LCPD than their siblings. The findings for diseases of the blood and blood-forming organs were less consistent, which possibly reflects etiologic heterogeneity. It should be noted that the statistical power for comparisons with siblings was much reduced because of smaller numbers, which influenced statistical significance. The closer matching of siblings as a comparison group might modify the magnitude of associations; genetic inheritance and early-life risks for cardiovascular diseases are shared more often between siblings than with an unrelated comparator.

This is one of the first studies to investigate whether patients with LCPD have greater risks for diseases of vascular origin, compared with a general population comparison group, with a large sample size and relatively long follow-up time. Because the onset of many cardiovascular diseases is in later life our study might have produced conservative estimates, because the majority of subjects were still relatively young.

Consequently, the numbers of events were small, and we used disease groups rather than specific diseases for the main analysis.

Our hypothesis of common risks for LCPD and cardiovascular diseases allows for either temporal sequence of disease diagnosis; it does not matter which disease occurs first. Because cardiovascular diseases predated LCPD in some cases, reduced physical exercise attributable to LCPD increasing the risk for cardiovascular diseases is unlikely to be the sole explanation for the association between the diseases, but such a mechanism hypothetically could contribute to increasing the magnitude of the association. In a study such as this, however, surveillance bias is a potential concern, because cardiovascular diseases might have been diagnosed incidentally during evaluation or treatment of LCPD. To address this, we examined the temporal sequence of diagnoses and excluded events in the 5 years after LCPD treatment; the associations remained.

The registry data used for this study did not include details of some risk factors relevant to these diseases, such as family history of disease, physical exercise, and smoking. However, it should be noted that these are not confounding factors in this study; we sought to identify an excess risk of cardiovascular diseases among patients with LCPD, which might be attributable to shared environmental exposures or inherited characteristics relevant to both diseases. It is of note that adjustment for socioeconomic index had little influence on our estimates, which indicates that broad social conditions (associated with characteristics such as smoking behavior) do not explain the association of these diseases. We used the Swedish Inpatient Register to identify diagnoses, the validity of which is generally high $^{52}$.

Bias attributable to diagnostic misclassification, if any, would be likely to move relative risks toward the null; therefore, the observed excess risks might be underestimates. Unfortunately, we did not have outpatient data. Because some diseases, such as hypertension, are generally diagnosed and treated in outpatient settings, it is likely that we underestimated the number of such diagnoses, reducing the number of events and our statistical power to detect associations.

\section{CONCLUSIONS}

Patients with LCPD had greater risks of cardiovascular diseases and also might be at higher risk of some conditions of the blood and blood-forming organs, such as nutritional and hemolytic anemia. These associations are consistent with the involvement of vascular pathologic conditions and other sources of insufficient blood supply to the femoral head in the pathogenesis of LCPD. 
Table1. Characteristics of the study subjects

Individuals with LCPD Individuals without LCPD

Total number

2579

13748

Male (\%)

1936 (75.1)

10408 (75.7)

Socioeconomic index:

Manual workers

$890(34.5)$

3940 (28.7)

Non-manual workers

$460(17.8)$

2579 (18.8)

Professionals

204 (7.9)

1548 (11.3)

Farmers

$29(1.1)$

263 (1.9)

Self-employed workers

133 (5.2)

623 (4.5)

Others

Table 2: Association between Legg-Calvé-Perthes disease (LCPD) and cardiovascular diseases and diseases of the blood and blood-forming organs, 2579 individuals with LCPD (75.1\% male) and 13748 individuals without LCPD (75.7\% male)

\begin{tabular}{|c|c|c|c|c|}
\hline \multirow[t]{2}{*}{ Disease (ICD-9 code) } & \multirow{2}{*}{$\begin{array}{l}\text { Individuals } \\
\text { with LCPD, \% }\end{array}$} & \multirow{2}{*}{$\begin{array}{l}\text { Individuals } \\
\text { without } \\
\text { LCPD, \% }\end{array}$} & \multicolumn{2}{|c|}{ Hazard Ratio (95\% Confidence Interval) } \\
\hline & & & Unadjusted & $\begin{array}{l}\text { Adjusted for } \\
\text { Socioeconomic Index }\end{array}$ \\
\hline \multicolumn{5}{|l|}{$\begin{array}{l}\text { Cardiovascular } \\
\text { diseases }(390-459)\end{array}$} \\
\hline No & 88.4 & 91.8 & Reference & Reference \\
\hline Yes & 11.6 & 8.2 & $1.70(1.47-1.94)$ & $1.70(1.48-1.95)$ \\
\hline \multicolumn{5}{|c|}{$\begin{array}{l}\text { Hypertensive diseases } \\
(401-405)\end{array}$} \\
\hline No & 96.2 & 97.9 & Reference & Reference \\
\hline Yes & 3.8 & 2.1 & $2.21(1.72-2.84)$ & $2.19(1.70-2.81)$ \\
\hline \multicolumn{5}{|c|}{$\begin{array}{l}\text { Ischemic heart diseases } \\
(410-414)\end{array}$} \\
\hline No & 96.5 & 97.3 & Reference & Reference \\
\hline Yes & 3.5 & 2.7 & $1.60(1.25-2.06)$ & $1.59(1.24-2.05)$ \\
\hline \multicolumn{5}{|c|}{$\begin{array}{l}\text { Pulmonary heart disease } \\
\text { and diseases of } \\
\text { pulmonary circulation } \\
(415-417)\end{array}$} \\
\hline No & 99.5 & 99.6 & Reference & Reference \\
\hline Yes & 0.5 & 0.4 & $1.48(0.80-2.71)$ & $1.25(0.67-2.33)$ \\
\hline \multicolumn{5}{|c|}{$\begin{array}{l}\text { Cerebrovascular diseases } \\
(430-438)\end{array}$} \\
\hline No & 96.9 & 98.0 & Reference & Reference \\
\hline Yes & 3.1 & 2.0 & $1.76(1.34-2.31)$ & $1.79(1.36-2.36)$ \\
\hline \multicolumn{5}{|c|}{$\begin{array}{l}\text { Diseases of arteries, } \\
\text { arterioles and capillaries } \\
(440-448)\end{array}$} \\
\hline No & 98.5 & 99.0 & Reference & Reference \\
\hline Yes & 1.5 & 1.0 & $1.92(1.30-2.83)$ & $1.91(1.29-2.82)$ \\
\hline
\end{tabular}


lymph nodes (451-459)

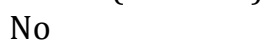

$\begin{array}{ll}97.2 & 98.2\end{array}$

Reference

Reference

Yes

2.8

1.8

$1.71(1.30-2.24)$

1.73 (1.31-2.28)

Diseases of the blood and

blood-forming organs (280289)

No
Yes
Peftion defects (286-

96.5

3.5

98.0

Reference

Reference

Coagulation defects (286-

287)

No

99.5

2.0

$1.96(1.53-2.52)$

1.94 (1.51-2.49)

Yes

0.5

99.6

Reference

Reference

Nutritional anemia (280-

0.4

$1.30(0.72-2.36)$

1.26 (0.69-2.29)

281)

No

99.1

99.5

Reference

Reference

Yes

0.9

0.5

2.24 (1.37-3.66)

2.32 (1.41-3.81)

Hemolytic anemia (282-

285)

No

98.6

99.3

Reference

Reference

Yes

1.4

0.7

$2.60(1.73-3.92)$

2.59 (1.72-3.92) 
Table 3: Risks of Cardiovascular Diseases and Diseases of Blood and Blood-Forming Organs Among Patients With LCPD, in Comparison With Same-Gender Siblings

\begin{tabular}{|c|c|c|}
\hline & Events & $\begin{array}{l}\text { Hazard Ratio }(95 \% \\
\text { CI) }\end{array}$ \\
\hline \multicolumn{3}{|c|}{$\begin{array}{l}\text { Patients and siblings with the least age } \\
\text { difference }(n=1552)\end{array}$} \\
\hline \multicolumn{3}{|c|}{ Cardiovascular diseases } \\
\hline Siblings & 58 & Reference \\
\hline Patients & 98 & $2.28(1.49-3.21)$ \\
\hline \multicolumn{3}{|c|}{$\begin{array}{l}\text { Diseases of the blood and blood-forming } \\
\text { organs }\end{array}$} \\
\hline Siblings & 31 & Reference \\
\hline Patients & 41 & $1.59(0.93-2.71)$ \\
\hline \multicolumn{3}{|c|}{ Patients and younger siblings $(n=721)$} \\
\hline \multicolumn{3}{|c|}{ Cardiovascular diseases } \\
\hline Siblings & 26 & Reference \\
\hline Patients & 47 & $1.57(0.91-2.72)$ \\
\hline \multicolumn{3}{|c|}{$\begin{array}{l}\text { Diseases of the blood and blood-forming } \\
\text { organs }\end{array}$} \\
\hline Siblings & 12 & Reference \\
\hline Patients & 16 & $1.10(0.47-2.59)$ \\
\hline \multicolumn{3}{|c|}{ Patients and older siblings $(n=831)$} \\
\hline \multicolumn{3}{|c|}{ Cardiovascular diseases } \\
\hline Siblings & 32 & Reference \\
\hline Patients & 50 & $2.88(1.66-5.00)$ \\
\hline \multicolumn{3}{|c|}{$\begin{array}{l}\text { Diseases of the blood and blood-forming } \\
\text { organs }\end{array}$} \\
\hline Siblings & 19 & Reference \\
\hline Patients & 25 & $2.00(1.00-4.00)$ \\
\hline
\end{tabular}

\section{REFERENCES}

1. Guille JT, Lipton GE, Szoke G, Bowen JR, Harcke HT, Glutting JJ. Legg-Calve-Perthes disease in girls. A comparison of the results with those seen in boys. The Journal of bone and joint surgery American volume. 1998;80(9):12561263.

2. Harrison MH, Blakemore ME. A study of the "normal" hip in children with unilateral Perthes' disease. The Journal of bone and joint surgery British volume. 1980;62-B(1):31-36.

3. Salter RB. The present status of surgical treatment for Legg-Perthes disease. The Journal of bone and joint surgery American volume. 1984;66(6):961-966.

4. Purry NA. The incidence of Perthes' disease in three population groups in the Eastern Cape region of South Africa. The Journal of bone and joint surgery British volume. 1982;64(3):286288.
5. Kim WC, Hiroshima K, Imaeda T. Multicenter study for Legg-Calve-Perthes disease in Japan. J Orthop Sci. 2006;11(4):333-341.

6. Hall AJ, Barker DJ, Dangerfield PH, Taylor JF. Perthes' disease of the hip in Liverpool. Br Med J (Clin Res Ed). 1983;287(6407):1757-1759.

7. Moberg A, Rehnberg L. Incidence of Perthes' disease in Uppsala, Sweden. Acta Orthop Scand. 1992;63(2):157-158.

8. Garcia Mata S, Ardanaz Aicua E, Hidalgo Ovejero A, Martinez Grande M. Legg-CalvePerthes disease and passive smoking. Journal of pediatric orthopedics. 2000;20(3):326-330.

9. Hall AJ, Barker DJ, Dangerfield PH, Osmond C, Taylor JF. Small feet and Perthes' disease. A survey in Liverpool. The Journal of bone and joint surgery British volume. 1988;70(4):611613.

10. Rao BS, Joseph B, Chacko V, Hall AJ. Altered skeletal growth in Perthes' disease: an 
anthropometric study of children from rural India. Journal of pediatric orthopedics Part $B$. 1995;4(1):91-94.

11. Wynne-Davies R, Gormley J. The aetiology of Perthes' disease. Genetic, epidemiological and growth factors in 310 Edinburgh and Glasgow patients. The Journal of bone and joint surgery British volume. 1978;60(1):6-14.

12. Lappin K, Kealey D, Cosgrove A, Graham K. Does low birthweight predispose to Perthes' disease? Perthes' disease in twins. Journal of pediatric orthopedics Part B. 2003;12(5):307310.

13. Eckerwall G, Wingstrand H, Hagglund G, Karlberg J. Growth in 110 children with LeggCalve-Perthes' disease: a longitudinal infancy childhood puberty growth model study. Journal of pediatric orthopedics Part B. 1996;5(3):181-184.

14. Liu SL, Ho TC. The role of venous hypertension in the pathogenesis of Legg-Perthes disease. A clinical and experimental study. The Journal of bone and joint surgery American volume. 1991;73(2):194-200.

15. Green NE, Griffin PP. Intra-osseous venous pressure in Legg-Perthes disease. The Journal of bone and joint surgery American volume. 1982;64(5):666-671.

16. de Camargo FP, de Godoy RM, Jr., Tovo R. Angiography in Perthes' disease. Clinical orthopaedics and related research. 1984(191):216-220.

17. Alpaslan AM, Aksoy MC, Yazici M. Interruption of the blood supply of femoral head: an experimental study on the pathogenesis of Legg-Calve-Perthes Disease. Arch Orthop Trauma Surg. 2007;127(6):485-491.

18. Axer A, Schiller MG. The pathogenesis of the early deformity of the capital femoral epiphysis in Legg-Calve-Perthes syndrome (L.C.P.S.). An arthrographic study. Clinical orthopaedics and related research. 1972;84:106-115.

19. Catterall A. Natural history, classification, and x-ray signs in Legg-Calve-Perthes' disease. Acta Orthop Belg. 1980;46(4):346-351.

20. Eldridge J, Dilley A, Austin H, M EL-J, Wolstein $\mathrm{L}$, Doris J, et al. The role of protein $\mathrm{C}$, protein $\mathrm{S}$, and resistance to activated protein $\mathrm{C}$ in LeggPerthes disease. Pediatrics. 2001;107(6):13291334.

21. Balasa VV, Gruppo RA, Glueck CJ, Wang P, Roy DR, Wall EJ, et al. Legg-Calve-Perthes disease and thrombophilia. The Journal of bone and joint surgery American volume. 2004;86$\mathrm{A}(12): 2642-2647$.

22. Glueck CJ, Glueck HI, Greenfield D, Freiberg R, Kahn A, Hamer T, et al. Protein C and S deficiency, thrombophilia, and hypofibrinolysis: pathophysiologic causes of
Legg-Perthes disease. Pediatr Res. 1994;35(4 Pt 1):383-388.

23. Levin C, Zalman L, Shalev S, Mader R, Koren A. Legg-Calve-Perthes disease, protein $\mathrm{C}$ deficiency, and beta-thalassemia major: report of two cases. Journal of pediatric orthopedics. 2000;20(1):129-131.

24. Lopez-Franco M, Gonzalez-Moran G, De Lucas JC, Jr., Llamas P, de Velasco JF, Vivancos JC, et al. Legg-perthes disease and heritable thrombophilia. Journal of pediatric orthopedics. 2005;25(4):456-459.

25. Socialstyrelsen. Klassifikation av sjukdomar och hälsoproblem 1997 - Systematisk förteckning (KSH97) 1996.

26. WHO. International Classification of Diseases (ICD). Published 2009. Accessed 7th January, 2010.

27. Statistics Sweden. Bakgrundsfakta till befolknings- och välfärdsstatistik (The MultiGeneration Registry). Örebro: Statistics Sweden; 2001.

28. Rosendaal FR, Reitsma PH. Genetics of venous thrombosis. J Thromb Haemost. 2009;7 Suppl 1:301-304

29. Hresko MT, McDougall PA, Gorlin JB, Vamvakas EC, Kasser JR, Neufeld EJ. Prospective reevaluation of the association between thrombotic diathesis and legg-perthes disease. The Journal of bone and joint surgery American volume. 2002;84-A(9):1613-1618.

30. Clarke R, Peden JF, Hopewell JC, Kyriakou T, Goel A, Heath SC, et al. Genetic variants associated with Lp(a) lipoprotein level and coronary disease. The New England journal of medicine. 2009;361(26):2518-2528.

31. Erqou S, Kaptoge S, Perry PL, Di Angelantonio E, Thompson A, White IR, et al. Lipoprotein(a) concentration and the risk of coronary heart disease, stroke, and nonvascular mortality. JAMA : the journal of the American Medical Association. 2009;302(4):412-423.

32. Hirano T, Iwasaki K, Yamane Y. Osteonecrosis of the femoral head of growing, spontaneously hypertensive rats. Acta Orthop Scand. 1988;59(5):530-535.

33. Lenfant C. Low birth weight and blood pressure. Metabolism. 2008;57 Suppl 2:S32-35.

34. Strufaldi MW, Silva EM, Franco MC, Puccini RF Blood pressure levels in childhood: probing the relative importance of birth weight and current size. Eur J Pediatr. 2008;168(5):619624.

35. Kosecik M, Erel O, Sevinc E, Selek S. Increased oxidative stress in children exposed to passive smoking. Int J Cardiol. 2005;100(1):61-64.

36. Aycicek A, Ipek A. Maternal active or passive smoking causes oxidative stress in cord blood. Eur J Pediatr. 2008;167(1):81-85.

37. Lawlor DA, Najman JM, Sterne J, Williams GM, Ebrahim S, Davey Smith G. Associations of 
parental, birth, and early life characteristics with systolic blood pressure at 5 years of age: findings from the Mater-University study of pregnancy and its outcomes. Circulation. 2004;110(16):2417-2423.

38. Theron J. Angiography in Legg-Calve-Perthes disease. Radiology. 1980;135(1):81-92.

39. Iwasaki K, Suzuki R, Okazaki T, Ikeda S, Inoue Y, Shimauchi R. The haemodynamics of Perthes' disease. An intraosseous venographic study combined with measurement of the intramedullary pressure. Int Orthop. 1982;6(3):141-148.

40. Fadda M, Zirattu G, Espa E, Orani G. Morphological aspects of the synovial membrane and femoral epiphyseal cartilage in experimentally induced chronic anemia. Italian journal of orthopaedics and traumatology. 1992;18(2):271-277.

41. Ebong WW, Kolawole TM. Aseptic necrosis of the femoral head in sickle-cell disease. British journal of rheumatology. 1986;25(1):34-39.

42. Ebong WW. Avascular necrosis of the femoral head associated with haemoglobinopathy. Trop Geogr Med. 1977;29(1):19-23.

43. Rand C, Pearson TC, Heatley FW. Avascular necrosis of the femoral head in sickle cell syndrome: a report of 5 cases. Acta Haematol. 1987;78(2-3):186-192.

44. Orzincolo C, Castaldi G, Scutellari PN, Bariani L, Pinca A. Aseptic necrosis of femoral head complicating thalassemia. Skeletal Radiol. 1986;15(7):541-544.

45. Glueck CJ, Brandt G, Gruppo R, Crawford A, Roy $\mathrm{D}$, Tracy $\mathrm{T}$, et al. Resistance to activated protein $\mathrm{C}$ and Legg-Perthes disease. Clinical orthopaedics and related research. 1997(338):139-152.

46. Yilmaz D, Karapinar L, Karapinar B, Ozturk H, Kavakli K. Evaluation of anticoagulant system in Turkish children with Perthes disease. Pediatr Int. 2005;47(1):43-48.

47. Glueck CJ, Tracy T, Wang P. Legg-Calve-Perthes disease, venous and arterial thrombi, and the factor $\mathrm{V}$ Leiden mutation in a four-generation kindred. Journal of pediatric orthopedics. 2007;27(7):834-837.

48. Arruda VR, Belangero WD, Ozelo MC, Oliveira GB, Pagnano RG, Volpon JB, et al. Inherited risk factors for thrombophilia among children with Legg-Calve-Perthes disease. Journal of pediatric orthopedics. 1999;19(1):84-87.

49. Gallistl S, Reitinger T, Linhart W, Muntean W. The role of inherited thrombotic disorders in the etiology of Legg-Calve-Perthes disease. Journal of pediatric orthopedics. 1999;19(1):82-83.

50. Kechli AM, Wilimas JA, Pui CH, Park VM, Tonkel S, Deitcher SR. Factor V Leiden and other hypercoagulable state mutations are not associated with osteonecrosis during or after treatment for pediatric malignancy.J Pediatr. 1999;134(3):310-314.

51. Schmitz A, Pfortner J, Protzel A, Harbrecht U. [Incidence of thrombophilic factor V Leiden and prothrombin G20210A mutation in Perthes disease--a pilot study]. Z Orthop Ihre Grenzgeb. 2001;139(2):143-146.

52. Socialstyrelsen. Kvalitet och innehåll i patientregistret. Stockholm, Sweden: Patientregistret, Epidemiologiskt Centrum, Socialstyrelsen; 2009. 